\title{
Policy Response on Land Degradation Induced by Large-scale Commercial Farming in Benishangul-Gumuz Region, North Western Ethiopia
}

\author{
Temesgen Disassa Marru ${ }^{1} \quad$ Shishay Kiros Weldegebriel ${ }^{2 *}$ \\ 1 Ph.D. Candidate in Urban and Regional Studies at Ethiopian Civil Service University, Addis Ababa, Ethiopia \\ 2 Ph.D. in Environment and Climate change resilience
}

\begin{abstract}
Understanding the major causes of agricultural land degradation is a fundamental step for finding possible solutions to mitigate farmland degradation. This article is focused on studying the causes of agricultural land degradation and identifying possible policy responses as well as directions to overcome the farmland and related resources degradation challenges. This study employed multiple data sources and a combination of policy documents, spatial data and information from the field through structured observation were utilized. Based on the land policy analysis, the major bottlenecks on efficient and effective implementation of the policy directions and legal frameworks were lack of awareness and sense of ownership; specific land use policy; institution responsible for land administration and use, to support and coordinate stakeholders efforts; mechanisms to build the capacity of implementers, beneficiaries, and how to disseminate the information for the public; attention for research and development to prepare land use plan in line with the dynamism of land use and cover change. Rights to use of common-pool resources were also a neglected aspect of land policy. Particularly in the Benshangul-Gumuz region, the majority of the local communities depend on common-pool resources such as forest lands, rangelands and wetlands for their livelihoods. On top of this, there were some constraints in the legal frameworks of the region: enforcement mechanisms for violations of the provision on land management are referred to relevant institutions and bodies; customary land right is not properly recognized in proclamations; and the ceiling for holding size not determined based on the in-depth study of the agro-ecological conditions, farming practices and customary landholdings system in the region. Thus, policymakers need to consider these drivers and make sound decisions during decision makings.
\end{abstract}

Keywords: Land policy, legal framework, land degradation, and large-scale commercial farming

DOI: $10.7176 / \mathrm{JNSR} / 12-18-02$

Publication date:September $30^{\text {th }} 2021$

\section{Background of the problem}

Land deterioration has recently become a worldwide concern (Le et al., 2014). Around a quarter of the worldwide land area is expected to be degraded, affecting around 1.5 billion people in all agro-ecologies around the globe (Bai et al., 2008). This is a major issue in Ethiopia, where more than 85 percent of the land has been degraded in some way (Gebreselassie, 2016). To achieve the aim of zero net deterioration, initiatives to reduce land deprivation would have to be multiplied significantly (Le et al., 2014).

Land degradation, according to (Hurni et al. 2010), is defined as "any process that reduces the capacity of land resources to fulfil key activities and services in ecosystems as a result of two interlocking complex systems: the natural ecosystem and the human social system." The success or failure of resource management is determined by the interactions between the two systems. Chemical degradation namely acidification, salinization, fertility depletion, and decreased retention capacity, physical degradation of crusting, compaction, and hardsetting, and biological degradation including a reduction in total and biomass carbon, and decline in land biodiversity are the main processes of land degradation (WMO 2005 cited in Temesgen, 2014). It is a continual process that has, nevertheless, become a major worry that affects food security and national prosperity, as well as the livelihood of practically everyone on the planet (Bezuayehu et al. 2002).

According to Berry (2003), loss of land resource productivity is a momentous problem in Ethiopia, and the problem is anticipated to become much more significant in the future as the country's population grows. Rapid population expansion, severe soil erosion, deforestation, low vegetative cover, and uneven crop and livestock production are the main drivers of land degradation in Ethiopia (Girma, 2001). Additional elements inducing the degradation processes influenced by man include topography, soil types, and agro-ecological characteristics (Paulos 2001).

Similarly, the Benishangul Gumuz region is endowed with more pristine land and natural resources. Cropland expansion, deforestation, shifting cultivation, a squatter settlement in forest land, water and wind erosion, forest fire, tenure insecurity, free grazing, and the expansion of large-scale commercial agricultural investment are all major causes of land degradation in this region, and the livelihoods of the local people are heavily reliant on land and other related resources (Woyessa, 2016). 
BGR recently prepared an estimated quantity of 1.4 million hectares of potentially available land for investors, as indicated in (MOARD, 2009). This is an indicator that the land resource is under stress in a short period. The land that has been prepped and transferred for potential investors is forestland, bushland, grassland, and potential ecosystem service areas, not banned land. However, large-scale commercial farming has some negative externalities, such as land degradation, deforestation, water resource depletion, chemical pollution, wetlands decline, reduced carbon stocks, resource competition, and loss of rights for local communities, in addition to its positive externalities.

Therefore, the objectives of this study were: to analyze land degradation derived by large-scale commercial farming, identifying possible policy responses and suggest possible directions to overcome the land and related resources degradation.

\section{Materials and Methods}

\subsection{Description of Benishangul-Gumuz Region}

The study was conducted in Benshanguel-Gumuz Region (BGR), particularly, in the Metkele Zone, of the three administrative zones of the Region. BGR is located in the north-western part of Ethiopia and is one of nine regional states in Ethiopia. It is estimated to have a total area of $50,380 \mathrm{~km}^{2}$ and a population density of 22.4 persons per $\mathrm{km}^{2}$. The region has a total population of 1, 127,001 according to CSA (2017).

With an altitude ranging between $558 \mathrm{~m}$ to $2729 \mathrm{~m}$ above sea level, and an average daily temperature of 20 $25^{\circ} \mathrm{C}$, it is endowed with diverse vegetation cover and minerals. However, the majority of its area (75\%) falls under the lowland category, with a maximum daily temperature of up to $34^{\circ} \mathrm{C}$ during the hottest periods. The onset and offset of the rainy period in the region in May and October, respectively, and the mean annual precipitation ranges between 500-1800 mm (Daie, 2012). The study area is considered a destination for largescale commercial agricultural investment projects. The large-scale tracks of agricultural land acquisition are a recent phenomenon.

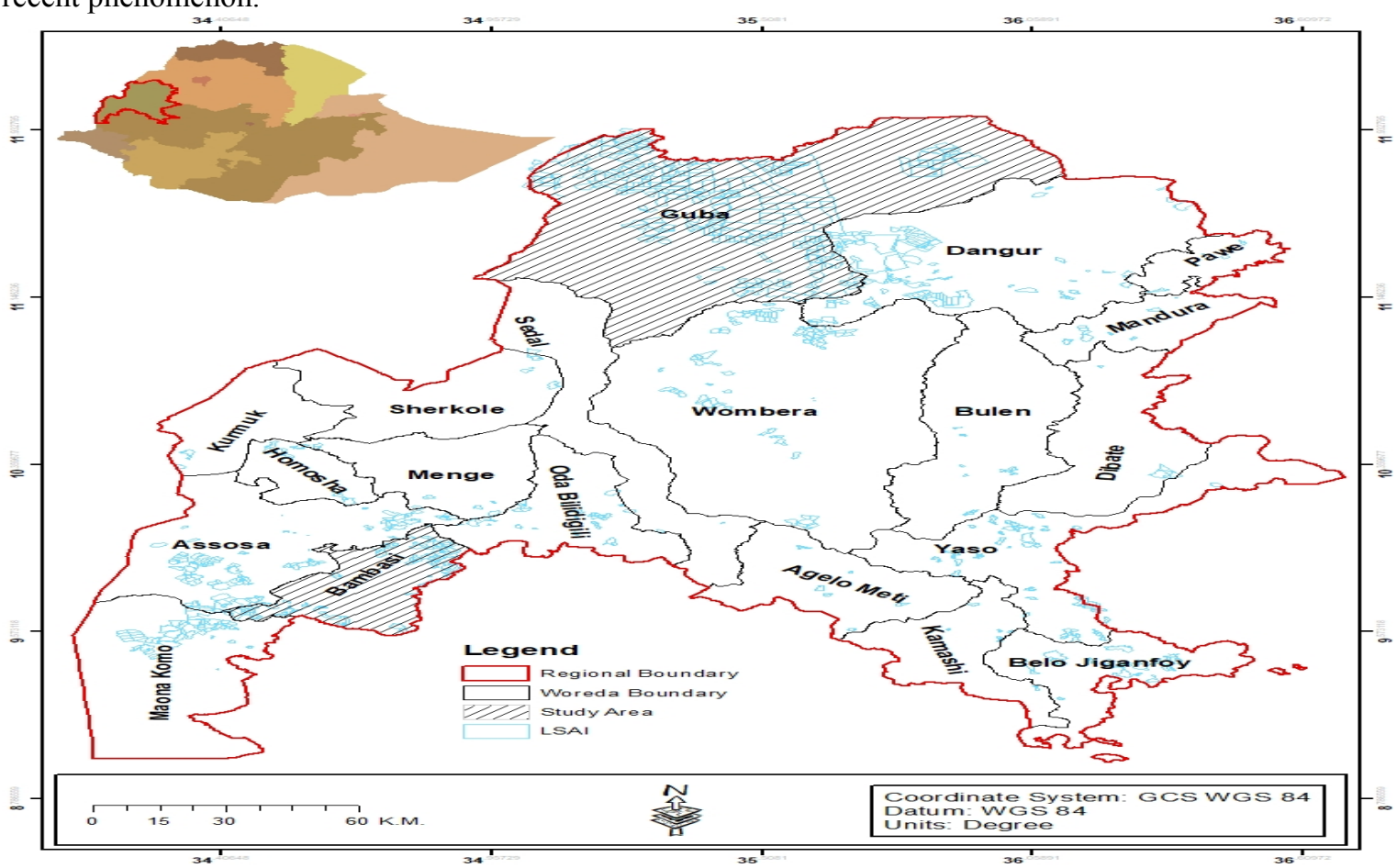

Source: Authors

Figure 1: Map of Benishangul-Gumuz Region.

\subsection{Methods}

The article utilized a qualitative research approach based on an exhaustive desk review of secondary and primary data sources from different sources. Methodologically, different techniques were employed: identifying the policies, strategies and legal frameworks specific for land degradation; reviewing related policies, legal frameworks, journals articles and empirical study to analyze their implications, to some extent conceptualizing the practices and challenges in the selected study area. The qualitative data were analyzed using document review, narratives and for map preparation and land use/land cover analysis ERDAS 2015 and Arc GIS version, 10.5 was utilized. The quantitative secondary source of data was analyzed using SPSS version 25. 


\section{Results}

\section{Analysis of policies and legal frameworks response on agricultural land degradation}

\subsection{Trends of Land Tenure policy}

The Ethiopian tenure or land holding system, which is divided into three historical periods, reflects the policies of the various governments. Feudalistic Ethiopia was ruled by feudal lords, and the landholding system was set up to favour the feudal lords at the expense of peasants and city dwellers. The concept of private land ownership was introduced throughout the imperial ages, but it was not implemented because the traditional tenure system was more prominent. During the Derge era, the revolution's phrase "land to the tiller" was practically applied. Nonetheless, the proclamations have effectively ended the possibility of private property ownership.

As a result, farmers were simply given the right to use their land. The Ethiopian constitution and land regulations have broadened this use right, allowing inheritance, lease, and donation rights that were formerly restricted by the Derge proclamation. The common aspect of both the Derge and FDRE land policies is the prohibition on individual people holding land and having sole authority over its exchange and sale. Both regimes' land policies are unable to persuade land users to invest in land management to assure the long-term usage of land resources (Ayana, 2013). Furthermore, the customary land tenure system is the principal land tenure system in Benshangul Gumuz. This tenure structure is incompatible with Ethiopian land legal frameworks, creating an atmosphere conducive to forestland invasion and resource overexploitation.

\subsection{Policies of land and related resources}

Land and land-related resources are the subjects of some policies in Ethiopia, including rural and urban land policy, forest policy, and environmental policy. The overview of land and environmental policies was reviewed in this examination. Ethiopia's land policy maintains that land belongs to the people and is administered on their behalf by the federal and provincial governments (FDRE, 2002). As stated in the policy document, some provisions on land management to minimize land degradation and ensure sustainable use of land resources include taking measures to increase land productivity and implementing strategies for alternative productive uses of hillsides, sloping lands, forest, and marginal lands to ensure their long-term viability.

As a result, to promote improved land usage, poverty, as well as backward and restricted agricultural practices, must be addressed. Farmers will be less likely to expand into forests and hillside areas if their productivity per landholding increases, which would otherwise exacerbate soil erosion. However, only if suitable and appropriate uses can be found for hillsides and forested areas can they be most effectively conserved. As a result, two tactics were combined in the approach. On the one hand, it is preferable to design a technological package that will aid in increasing land productivity and establishing alternative revenue streams on the various types of land that farmers have access to.

In 2010, the Benishangul-Gumuz region passed its regional rural land administration and use policy to ensure the sustainable and continuous use of natural resources, particularly rural land, while maintaining ecological balance and good governance. In general, the policy emphasizes the use of land in a way that optimizes its contribution to the overall development as the direction that governed development policies and strategies, particularly agricultural development policies and strategies. As a result, judicious use of a land resource is expected to contribute to long-term development by increasing agricultural productivity.

\subsection{Legal Frameworks}

Despite adopting a free-market economic philosophy, the new government has decided to keep all rural and urban land under public control. Both urban and rural land belongs to the state and the Ethiopian people, according to the Federal Democratic Republic of Ethiopia (FDRE) Constitution of 1995. Land policy critics claim that the lack of tenure security for land users gives little or no motivation to invest in long-term land improvement measures to boost land productivity. It has the potential to exacerbate land degradation due to soil mining and problems with common resource utilization.

Furthermore, present land rights may not be an ideal method for storing knowledge about the rights that come with ownership. Furthermore, the Federal Government has sole authority to create laws governing the use and conservation of land and other natural resources in the country (Article 51(5) of the Constitution). Land and natural resources must be managed in harmony with federal laws (Article 52(2)(d) of the Constitution). Despite the fact that for the time being, regions enact their land laws through delegation.

In 2005, the FDRE rural land administration and land use proclamation were adopted in accordance with the policy direction and constitution. It succeeds Proclamation No. 89/1997, which was issued in 1997. The pillars of the FDER rural land administration and usage Proclamation No.456/2005 focus on proper land use to reduce land degradation: (1) developing and implementing a sustainable rural land use planning based on the country's various agro-ecological zones to sustainably conserve and develop natural resources; (2) establishing legal conditions that are conducive to enhancing and strengthening farmers' land use rights to encourage them to take the necessary conservation measures in areas where mixed is present. (3) Establishing a favourable rural 
land administration system that promotes natural resource protection and management while also encouraging private investment in pastoralism areas with communal landholding systems based on tribes.

In light of the pillars mentioned above, the BGR rural land administration and use proclamation impose certain obligations on rural land beneficiaries to protect, conserve, and use the land sustainably, with a particular focus on land utilization and environmental protection in accordance with the federal forest resources development, conservation, and protection and utilization proclamation. Planting trees, caring for them, and making proper use of them where there are no naturally grown trees in the holding and land region. Furthermore, mother trees in down sloped areas should number at least a hundred, while plain areas should have 60 to 70 trees. For land slopes below 30 percent, soil conservation and water collection methods should be used; for land slopes, 31 percent to 45 percent usage for annual crop production, plain contour or other favourable farming systems should be used. Land slopes more than 45 percent should be used for tree planting, perennial plant development, and animal fodder development rather than farming and free grazing.

Holding within the farmland and water sites in the area, as well as streams in the vicinity, adequate treatment and care are required to avoid harm while farming. Furthermore, to maintain biodiversity, it is recommended that trees that provide habitat for wildlife, birds, and endangered tree species under protection such as the Wanza, Zobi, Kerero, Zegba, Koso, Desert palm tree, and others not be chopped down. If the land is near a river or gorge slopes or areas, any beneficiary must assume a distance of more than 500 meters from the riverbank, water bodies, gorge areas, or similar land with a depth of more than 10 meters for farming and engage in various soil and water conservation activities such as terracing to avoid soil and water pollution. Any organization having land use rights should take care of and maintain its holdings. In particular, any private investor or entity having land use rights is required to submit a land utilization plan for approval and implementation in addition to complying with these duties. Large-scale commercial farming initiatives, on the other hand, rarely follow the policy and legal framework's guidelines, as seen in Figure 2. This is a typical case of ineffective law enforcement.


Source: Authors, 2020

Figure 2: Typical Large-scale Commercial Farm 
Furthermore, in 1997, the Ethiopian government created an environmental policy to prevent negative environmental consequences and promote sustainable agriculture through the conservation of natural resources. The goal of the policy was to attain sustainable development without threatening the long-term viability of both man-made and natural resources. The policy's overall goal, as stated in the document, is to:

To improve and enhance the health and quality of life of all Ethiopians, as well as to promote sustainable social and economic development through sound management and use of natural, human-made, and cultural resources, as well as the environment as a whole, to meet the needs of the current generation while not jeopardizing future generations' ability to meet their own needs (FDRE, 1997).

In line with this, the federal government enacted Proclamation No.299/2002, a proclamation concerning environmental impact assessment (EIA), to control the environment and protect the total clearance of forests by investors. Due to the proliferation of large-scale development projects such as dams, commercial agriculture, irrigation systems, and other similar projects that have a negative environmental impact, EIA is a concern for governments all over the world.

Rural land management and usage proclamation No.85/2010, regulation No.44/2011, and directive No. o18/2006 were also issued by the regional government. One of the goals of the law is to improve the conditions for long-term investments and promote rapid and sustainable rural development. Investors who use investment lands for commercial agriculture without first obtaining an EIA must additionally design and implement an environmental management plan (EMP) to address the numerous environmental consequences and recommended mitigation strategies connected to occupational hazards and risks.

\section{Practices EIA in large-scale commercial agricultural investment (LSAI) projects}

In terms of environmental management practices of large-scale commercial agricultural investment projects in the region, out of 446 sample investment projects, 206 (46\%) have ESIA/EMP and 240 (54\%) do not (Figure 3). According to the data, the vast majority of investment projects perform their land development activities without the use of an ESIA/EMP. This is in contrast to EIA Proclamation No. 299/2002, which stated that undertaking an environmental impact assessment (EIA) is required for certain types of projects, whether they are undertaken by public or private entities.

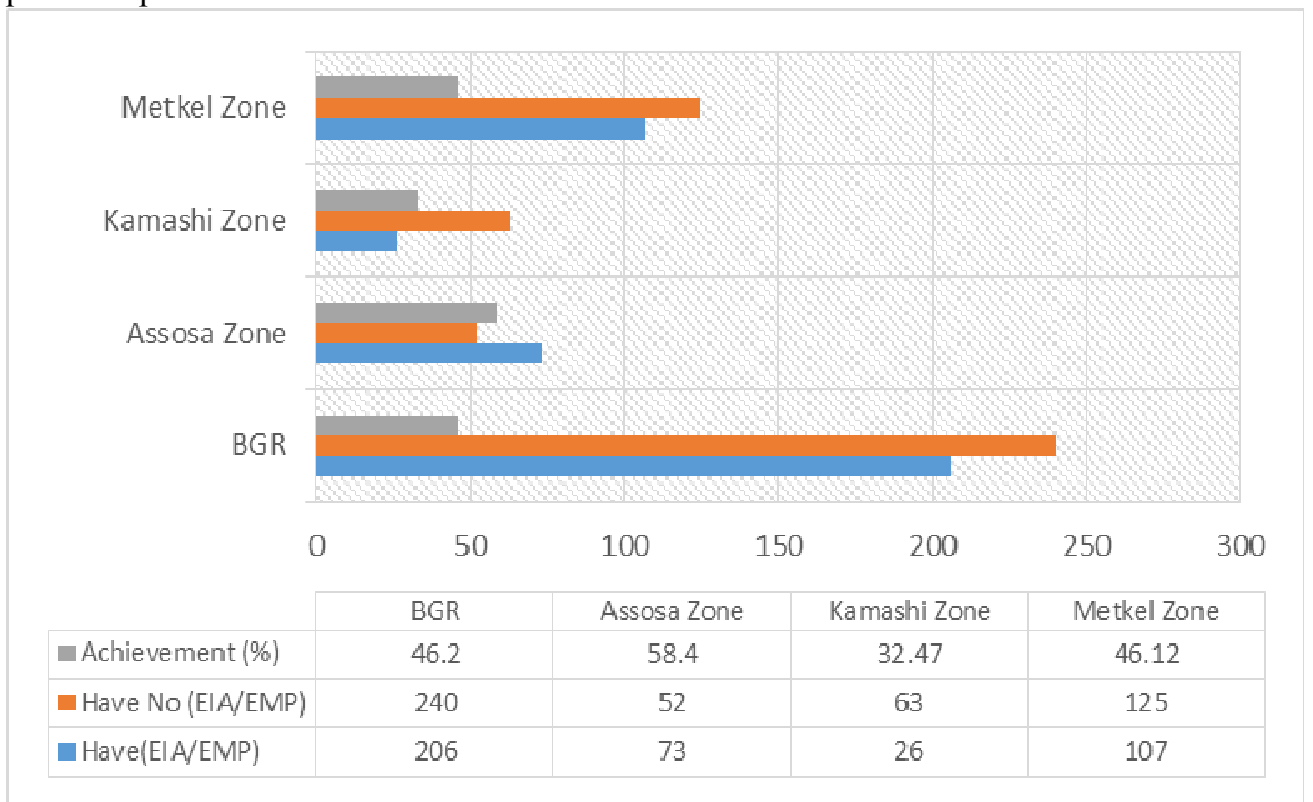

Source: Authors based on Regional BOLAEPI data, 2020

Figure 3: Practices Environmental Impact Assessment in LSAI projects

The data shows that the fundamental element for the above-mentioned provisions is that land and related resources must be appropriately held and used for better services on a long-term basis. This also means that there is a lack of awareness, ownership, and crucial implementation restrictions.

Concerning sample area for remote sensing satellite image data acquisition, the Guba district (Figure 4) was selected based on large-scale commercial agricultural investment firms' concentration $(>=167$ firms out of 446 lately functional firms). 


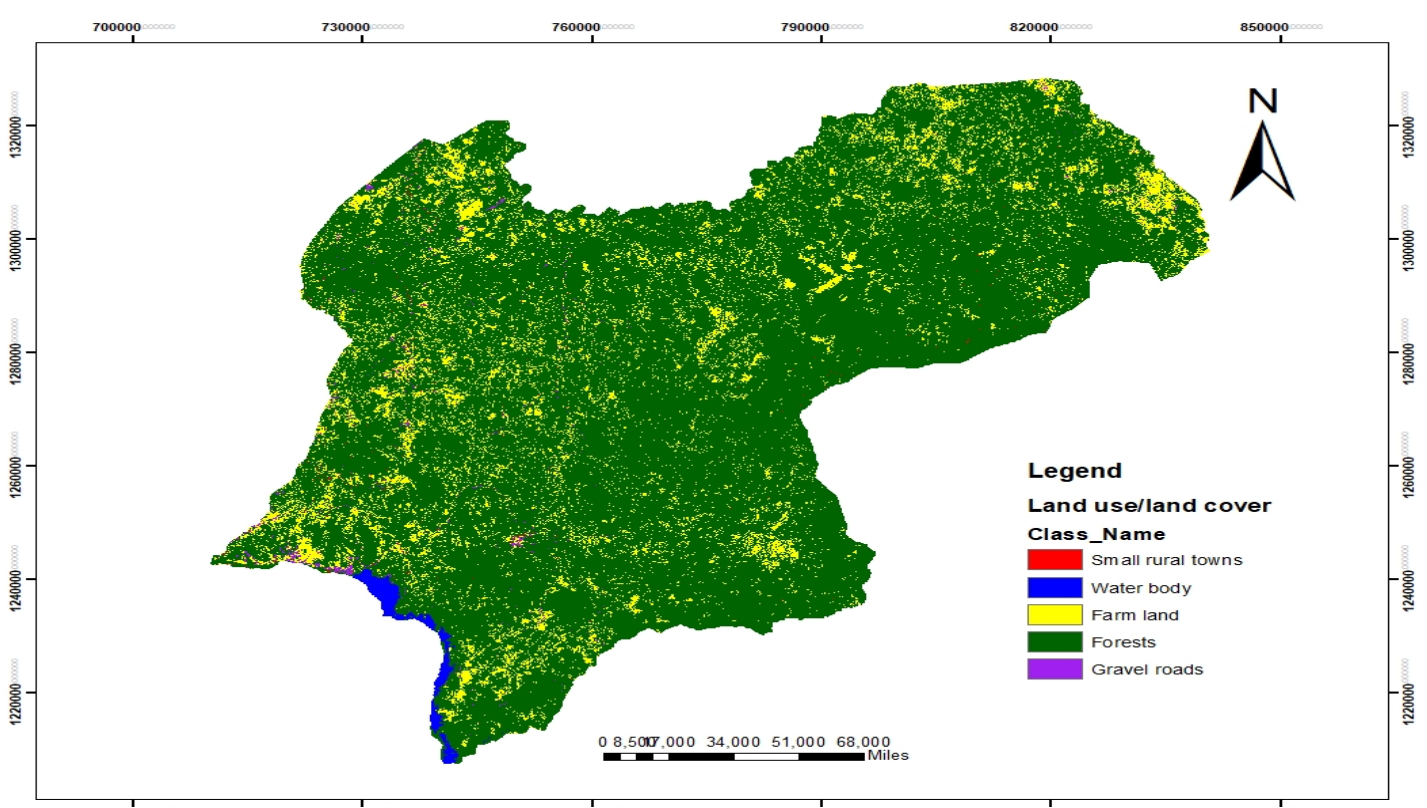

Figure 4: Land use/land cover map for the year 2021 in Guba District

Source: Authors, 2021

The above figure(Figure 4) results from the classified image illustrate currently the sampled area based on the satellite imageries data,6570003.73 ha $(86.24 \%)$ is forest, 94556.76 ha $(12.41 \%)$ farmland, 5365.57 ha $(0.7 \%)$ water body,4236.32 $(0.56 \%)$ gravel land, and 642.06 ha $(0.08 \%)$ are small towns. This data shows the dominant land use/land cover type is forest land (figure 5).

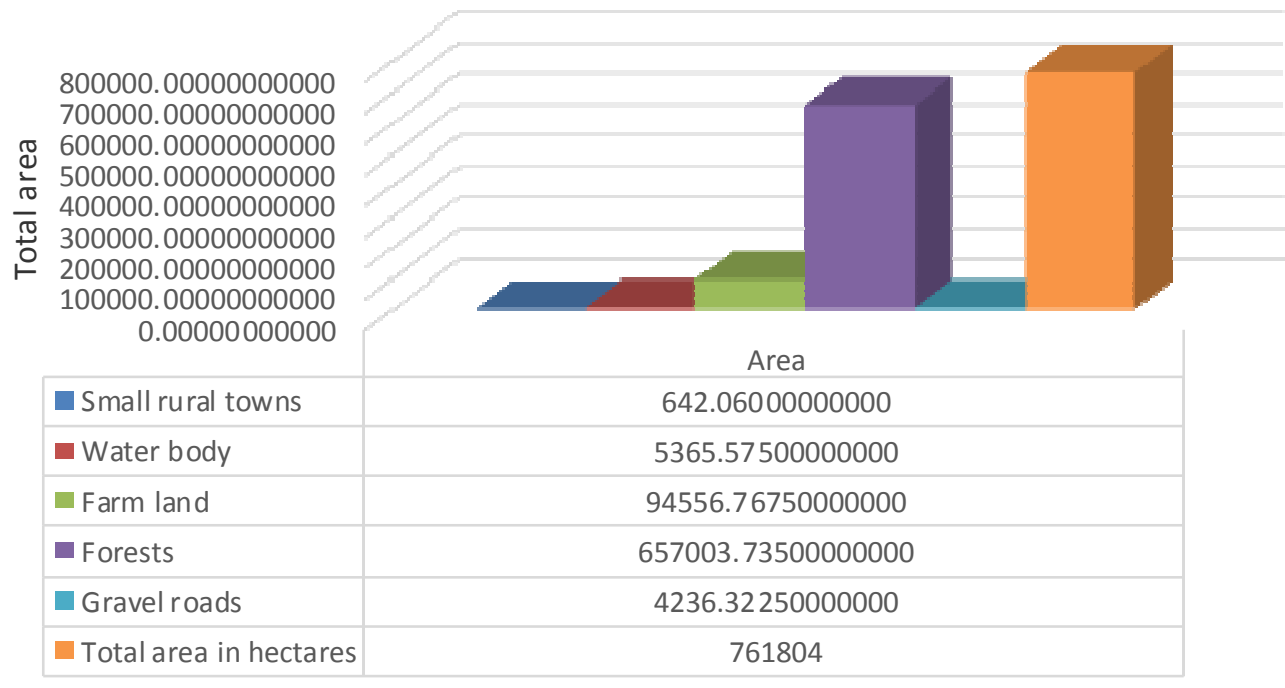

Figure 5: Area coverage of land use/land cover types (in hectares)

\section{Conclusions and recommendations}

In the study area, land degradation is a prevalent environmental issue. Low and declining agricultural output, chronic food insecurity, and rural poverty are all caused by it. Furthermore, land degradation has a direct impact on the type of plant grown in the area, as well as the availability of drinkable water, surface water volumes, aquifer depletion, and biodiversity loss. To influence how we utilize the land, as well as to assure agricultural production and environmental sustainability, sound land policy and land institutions are essential. Land policy and institutions must maintain pace in this regard, offering an equitable base for investment and land development while ensuring that impoverished people acquire new or alternative livelihood options and that their rights are protected. The policy direction must clearly state how to establish tools to raise public knowledge about the conservation and management of land and related resources.

Quantifying land use/cover is important for better understanding the state of environmental deterioration 
and preserving the ecosystem. They're useful tools for establishing a decision-making system, and they're crucial for ecosystem management. The establishment of land use and occupation by defining the proper land use policy is made possible by continuous monitoring of land usage.

In the policy direction, the methods for communicating with implementers and beneficiaries should be stated. Institutions must change to acknowledge customary land rights, comprehend indigenous agricultural management systems, and protect women's and marginalized groups' rights. As a result, national/regional land policies must provide clear guidance on how to maintain, use, and manage common-pool resources or communal lands (forestland, rangeland, wetlands) in low-lying places such as the Benshangul-Gumuz Region. Similarly, legal frameworks must include efficient enforcement mechanisms in addition to being in line with policy directives.

\section{Declaration of interest}

There are no competing interests declared by the authors.

\section{Ethics approval}

Not applicable.

\section{Consent to participate}

The authors need to accept and affirm that they have read and agreed to the manuscript's content, and that they are responsible for all aspects of the manuscript's accuracy and integrity. The article is unique, has never been published before, and is not currently being reviewed by another publication

\section{Consent for publication}

The authors have volunteered to have their original research published in this journal. The writers grant permission for the article to be published and identify themselves as the original publisher.

\section{Authors' contributions}

1) Temesegen Disassa Marru makes substantial contributions to conception and design, and/or acquisition of data, and/or analysis and interpretation of data;

2) Shishay Kiros weldegebriel contribution is on conceptual design; revising critically for important intellectual content, spatial data preparation and edited the manuscript.

\section{Authors' information}

1. Dr. Shishay kiros weldegebriel is a Ph.D. scholar in Environment and climate changes resilience. He has published 7 scientific works in international reputable journals.

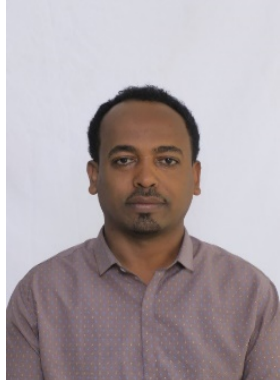

Email: shishaykiros@gmail.com

2. Temesgen Disassa Marru is a Ph.D. Candidate in Urban and Regional Studies in Ethiopian civil service university. He formerly served as a senior government official for 5 years as bureau head of environmental protection and land administration in Benishangul Gumuz regional state, Ethiopia

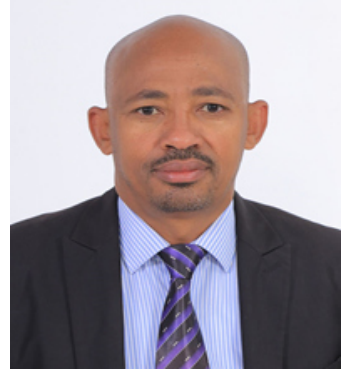

Email: marru4127@gmail.com 


\section{Acknowledgements}

We would like to express our gratitude to those institutions and individuals at the national, regional, and district levels who provided us with the data we needed for this study.

\section{References}

Ayana, A. N., Arts, B., \& Wiersum, K. F. (2013). Historical development of forest policy in Ethiopia: Trends of institutionalization and deinstitutionalization. Land Use Policy, 32, 186-196.

Bai, Z.G., Dent, D.L., Olsson, L. \& Schaepman, M.E. 2008. Proxy global assessment of land degradation. Soil Use and Management, 24, 223-234

Benishangul-Gumuz Region EPLAU (2010): Rural Land Administration and Use: Regulation No.44/2011. Asossa, Benishangul-Gumuz Region, Ethiopia

Benishangul-Gumuz Regon, EPLAU, (2010): Rural Land Administration and Use: Policy, and Proclamation No.85/2010. Asossa, Benishangul-Gumuz Region, Ethiopia.

Benishangul-Gumuz Regon, EPLAU, (2010): Rural Land Administration and Use: Directive No.018/2006. Asossa, Benishangul-Gumuz Region, Ethiopia

Berry L (2003). Land degradation in Ethiopia: its impact and extent in Berry L, Olson J. and Campbell D (ed): Assessing the extent, cost and impact of land degradation at the national level: findings and lessons learned from seven pilot case studies. Commissioned by a global mechanism with support from the World Bank.

Bezuayehu T, Gezahegn A, Yigezu A, Jabbar M and Paulos D (2002). Nature and causes of land degradation in the Oromiya Region: socio-economic and policy research working paper 36. International Livestock Research Institute.

FDRE, (2002). Policies, Strategies and Approaches to Rural Development. The Federal Democratic Republic of Ethiopia, Addis Ababa (Amharic).

FDRE,( 1995). The Constitution of the Federal Democratic Republic of Ethiopia. Federal Negarit Gazeta, firstyear No. 1, Addis Ababa

FDRE,( 2005). Rural Land Administration and Use Proclamation No.456/2005.Addis Ababa, Ethiopia.

FDRE,(1997). Environmental policy of Ethiopia.

FDRE,(2002). Environmental Impact Assessment Proclamation No.299/2002.

Gebreselassie, S., Kirui, O. K., \& Mirzabaev, A. (2016). Economics of land degradation and improvement in Ethiopia. In Economics of land degradation and improvement-a global assessment for sustainable development (pp. 401-430). Springer, Cham.

Girma T (2001). Land Degradation: A Challenge to Ethiopia. International Livestock Research Institute, Addis Ababa, Ethiopia. pp 815-823.

Hurni H, Solomon A, Amare B, Berhanu D, Ludi E, Portner B, Birru Y and Gete Z (2010). Land degradation and sustainable land management in the highlands of Ethiopia. In Hurni H, Wiesmann U (ed) with an international group of co-editors. Global change and sustainable development: A synthesis of regional experiences from research partnerships. Geographic Bernensia. 5:187-201.

Le, Q. B., Nkonya, E., \& Mirzabaev, A. (2016). Biomass productivity-based mapping of global land degradation hotspots. In Economics of land degradation and improvement-A global assessment for sustainable development (pp. 55-84). Springer, Cham.

MoARD (2009). Agricultural Investment Potential of Ethiopia. Addis Ababa.

Paulos D (2001). Soil and water resources and degradation factors affecting their productivity in the Ethiopian highland agro-ecosystems. Michigan State University Press. 8(1): 1-18.

Temesgen G, Amare B and Abraham Mahari (2014b). Evaluations of Land Use/Land Cover Changes and Land Degradation in Dera District, Ethiopia: GIS and Remote Sensing Based Analysis. International Journal of Scientific Research in Environmental Sciences. 2(6):199-208.

Woyessa, M. (2016). Land Acquisition for Commercial Agriculture in BGR, Ethiopia: Access, Utilization, and Impacts on Local Communities. PhD Dissertation, AAU Sociology Department, Addis Ababa, Ethiopia. 